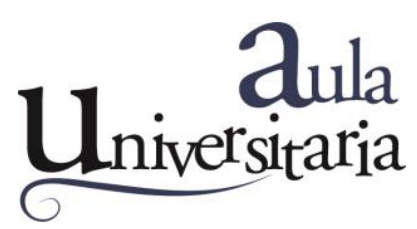

\title{
Propuesta para el uso pertinente del idioma español en medicina
}

\author{
D’OTTAVIO, María E.; D’OTTAVIO, Alberto E;2
}

\author{
Filiaciones institucionales \\ ${ }^{1}$ Licenciatura en Psicopedagogía. Universidad del Gran Rosario. \\ 2 Facultad de Ciencias Médicas y Consejo de Investigaciones, Universidad Nacional de Rosario.

\section{Correspondencia} \\ aedottavio@hotmail.com
}

\section{Resumen}

La medicina requiere el desarrollo de competencias específicas para la práctica profesional (docencia, investigación científica y/o asistencia). Entre ellas, y dentro de las habilidades comunicacionales, el empleo pertinente del idioma español suele quedar ensombrecido por el lenguaje técnico. Visto su progresivo deterioro diacrónico y cualquiera sea el ejercicio médico a llevar a cabo, este trabajo: (a) propone una factible secuencia reparadora en etapas de los "desaseos de la lengua", (b) intenta proveer, a su través, herramientas valiosas para que los profesionales interactúen con personas de diferente nivel cultural sin deteriorar la comunicación, y (c) efectúa complementarias reflexiones sobre su eventual implementación. La primera etapa persigue evitar: barbarismos, anglicismos y solecismos (queísmos y dequeísmos, empleo inadecuado de los adverbios donde y cuando, incorrecta asociación de tiempos del modo subjuntivo con el tiempo condicional del modo indicativo, equivocado empleo de los verbos haber y hallar, disonante uso de muletillas y expletivos, despeño en redundancias y frecuente confusión entre siglas, sigloides y acrónimos). La segunda etapa se centra en conocer el verdadero significado de palabras desconocidas, y también de aquellas supuestamente conocidas, así como en sus respectivas etimologías, y la última etapa incursiona en sinónimos, antónimos, parónimos, homónimos y epónimos.

\section{Palabras clave \\ uso | pertinencia |idioma español | medicina}




\section{Summary}

Medicine requires the development of specific skills for professional practice (teaching, scientific research and / or assistance). Among them, and within communication skills, the relevant use of the Spanish language, is often overshadowed by technical language. Given its progressive diachronic deterioration and whatever the medical exercise to be carried out, this paper: (a) proposes a feasible repairing sequence in stages of the language weaknesses, (b) intends to provide, through it, valuable tools for professionals to interact with people of different cultural levels without impair communication, and (c) make complementary reflections on its eventual implementation. The first stage seeks to avoid: barbarisms, Anglicism and, solecisms (queismo and dequeismo, inappropriate use of adverbs where and when, incorrect association of tenses of the subjunctive mode with the conditional tense of the indicative mode, wrong employment of the verbs haber and hallar, dissonant use of fillers and expletives, reluctance in redundancies and frequent confusion between initials and acronyms). The second stage focuses on knowing the true meaning of unknown words and even those supposedly known, as well as their respective etymologies, and the last stage ventures into synonyms, antonyms, paronyms, homonyms and eponyms.

\section{Keywords}

use / relevant / spanish language / medicine

\section{Marco referencial}

La medicina requiere el desarrollo de competencias específicas para la práctica profesional (docencia, investigación científica y/o asistencia). Entre ellas, y dentro de las habilidades comunicacionales, el empleo pertinente del idioma español suele quedar ensombrecido por el lenguaje técnico.

Sobre este particular, un catedrático español advierte acerca de «la desatención y uso ignorante del idioma por ciertos profesionales, colectivos diversos y "desaseados de la lengua" que utilizan las palabras por aproximación». Entre otras causas, atribuye tal descuido a: «la poca o nula lectura literaria, el esnobismo, la tropelía de extranjerismos —anglicismos, sobre todo- y la actitud ignorante de muchos oradores y responsables de la comunicación» sin dejar de subrayar que «el problema se retroalimenta por posturas inaceptables, incultas, autoritarias y dogmáticas». Asimismo, destaca el «insoportable desiderátum de lo "políticamente correcto" auspiciado por posturas acomodaticias amparadas en el relativismo, pusilanimidad o temor a enojar a los permanentemente airados defensores del edén vernáculo» para rematar expresando «me sitúo contrario a cuantos despojan a los vocablos de su auténtico significado para forzarlos a decir lo que no son» (Gil Extremera, 2017:18).

Congruentemente con lo reseñado, ambos autores en su rol de docentes universitarios, han apreciado en alumnos y graduados crecientes debilidades diacrónicas en el uso del rico idioma español. 
En ese marco referencial, el presente trabajo:

a) Propone una factible secuencia reparadora en etapas de tales «desaseos de la lengua» que, sin agotarlos en totalidad, comience la impostergable tarea, en línea con lo dicho por el precitado catedrático, de: «evitar errores y ayudar a una mejor redacción de artículos, memorias, ponencias, proyectos de investigación y tesis doctorales, porque la forma escrita, complemento de la oral, es imprescindible en una profesión donde abundan dictámenes, documentos, informes, misivas, manuscritos 0 textos diversos». (Gil Extremera:18)

b) Intenta proveer a su través, una herramienta imprescindible para que los profesionales interactúen con personas de diferente nivel cultural sin deteriorar la comunicación.

c) Efectúa complementarias reflexiones sobre su eventual implementación.

\section{Etapas a recorrer e ítems a considerar}

En consonancia con lo aceptado por la Real Academia de la Lengua Española (2019), la primera etapa podría estar centrada en:

- Evitar barbarismos (del griego bárbaro: acuñado inicialmente para referirse al habla de los persas, e ismos: actividad): comisión de errores orales y/o escritos en palabras. A modo de ejemplo, corresponde decir y escribir: fluido (no flúido); periferia (no perifería), estado o estadio (no estadío) y síndrome (no sindrome). Tampoco deben tildarse las palabras graves terminadas en $n$ (resumen, examen), los adjetivos demostrativos (este, ese, aquel con sus variantes de género y número) ni los pronombres demostrativos: esto, eso y aquello. En ese ítem nada ocioso resulta señalar que si bien al referirse al agua, aula o a área; entre otros sustantivos femeninos tónicos o átonos, se recurre al artículo el por razones de fonética histórica pero no se mantiene el masculino en caso de adjetivos demostrativos: esta agua, aula o área es correcto (este agua, aula o área es incorrecto)

- Obviar anglicismos ${ }^{1}$ que tienen palabras adecuadas en español para su reemplazo: resumen por abstract, trastorno por disorder, valor por level, tratamiento por management, aleatorizar por randomize, puntuación por score, grave por severe y acontecimiento por event, entre varias (Silva, 2019:645).

1 Palabra, expresión o giro de la lengua inglesa empleada en otro idioma. 
- Omitir solecismos (del griego soloicos: expresión contra las reglas como hacían los habitantes de Solos (Asia Menor), hablantes de un griego corrompido, e ismos: actividad): errores orales y/o escritos producidos en el modo de combinar y ordenar palabras y expresiones en una redacción o discurso (sintaxis).

Según propia experiencia, se cuentan entre los habituales:

a) el inapropiado uso de la conjunción que (queísmo) y el de ella precedida por la preposición de (de que) (dequeísmo). Así, correcto es decir me alegra que estudies esa disciplina y me alegro de que estudies esa disciplina pues ambas expresiones persisten eufónicas al reemplazar: que estudies esa disciplina por la palabra eso,

b) el empleo inadecuado de los adverbios donde y cuando. Acertado es decir y escribir: el alumno arribó y entonces fue cuando fue convocado (pues alude a tiempo), y no, donde fue convocado (ya que hace referencia a lugar),

c) la incorrecta asociación de tiempos del modo subjuntivo con el tiempo condicional del modo indicativo (considerado por algunos: modo subjuntivo, y otrora denominado modo potencial). Apropiado es decir y escribir si fuera o fuese tal... sería, o si hubiera o hubiese sido tal... habría sido. No lo es, en cambio, expresar: si yo sería...,

d) el equivocado empleo de los verbos haber y hallar. Si el verbo a utilizar puede reemplazarse por encontrar, el correcto es hallar y en caso contrario, es haber como dable es apreciar en los respectivos ejemplos: La estudiante no halla consuelo y la estudiante lamenta que no haya consuelo para ella,

e) el disonante uso de muletillas y expletivos. Cuando durante el discurso se completan pausas con reiterados: este, nada, eh, o sea, etc., la cacofonía resultante se denomina muletilla por devenir tales repeticiones indeseable apoyo discursivo. A su vez, el expletivo no tan cacofónico como el anterior y que se emplea para hacer más llena, intensa o armoniosa la frase, aunque no se necesite para entender su significado es conveniente soslayarlo. Resulta pertinente, entonces, evitar iniciar la alocución con bien, pues bien, bueno o tenemos que, 
f) el despeño en redundancias: repeticiones innecesarias como dable es apreciar al decir o escribir: la enorme mayoría, tengo mi opinión personal al respecto, vuelvo a reiterar mi disconformidad, ${ }^{2} \mathrm{y}$

g) la frecuente confusión entre siglas, sigloides y acrónimos. Las primeras se escriben sin puntos ni espacio entre cada letra y no se pluralizan (IAM: infarto agudo de miocardio); los sigloides lo hacen en mayúsculas combinadas con minúsculas (Renfe) y los acrónimos, en minúscula y de tal modo que resulta posible pronunciarlos como palabra (spanglish).

Por otra parte, la segunda etapa podría dedicarse a hacer hincapié en el significado de palabras desconocidas, y aún de aquellas, supuestamente conocidas, así como en sus respectivas etimologías (étimo = elemento verdadero, auténtico) en virtud de su valor orientador y la posibilidad de encontrar en ellas «ribetes sublimes y sorprendentes, fulgores valiosos y sugerencias 0 perfiles de misterio» (Gil Extremera:18).

Por último, en la tercera etapa convendría diferenciar:

a) sinónimos (del griego sin: unión; onomos: nombre): términos con diferente escritura e igual significado: droga, fármaco y medicamento, odontalgia y odontodinia, cefalalgia y cefalea.

b) antónimos (del griego anti: contra; onomos: nombre): términos con significado opuesto o contrario: microglobulia y macroglobulia, hipotensión e hipertensión, exoplasma y endoplasma, intracelular y extracelular.

c) parónimos (del griego para: al lado; onomos: nombre): términos de escritura o sonido parecido y distinto significado: bazo y vaso, carótida y parótida, intercelular e intracelular.

d) homónimos (del griego homo: igual; onomos: nombre) ${ }^{3}$

- homógrafos (del griego graphia: escritura): términos con idéntica escritura pero distinto significado: lengua y lengua, vaso y vaso, arteria y arteria, cólera y cólera.

- heterográfos (del griego heteros: distinto): términos con distinta escritura y significado: bacilo y vacilo.

\footnotetext{
${ }^{2}$ A diferencia de la redundancia, que carece de función justificadora para su uso, el pleonasmo (subir arriba, bajar abajo, verlo con los propios ojos) suele aceptarse por proveer mayor fuerza o énfasis a los dichos.

${ }^{3}$ Su asociación con los homófonos ha sido omitida ya que, según se pronuncien en español o en español rioplatense, pueden o no ser rotulados como tales.
} 
e) epónimos (del griego epi: sobre; onomos: nombre): nombres propios de personas, de personajes de ficción y mitológicos y de deidades de los que derivan palabras aceptadas por la Real Academia Española (épocas, ciudades, unidades, enfermedades, medios técnicos, etc.). Así, el síndrome de Down es epónimo en recuerdo del polémico hallazgo de John Langdon Hayden Down y el sándwich, lo es de su consumidor más que descubridor John Montagu, IV Conde de Sandwich. (Serra Valdés, 2016:82)

Sus interrogantes conexos serían, además de cuándo, cómo y dónde hacerlo, quiénes serían los encargados de ello, ya que los qué y por qué han sido debidamente explicitados.

Desde ya los planificadores curriculares serían los encargados de responder a los mismos partiendo de la base de que, para parte del alumnado, podría ser algo novedoso y para el resto, instancias reforzadoras de conocimientos y habilidades preexistentes.

En lo que a los autores de este trabajo concierne, propondrían su más temprano entrenamiento curricular posible, llevarlo a cabo a lo largo de la carrera toda en progresiva complejidad, y en cualquier situación y lugar de aprendizaje médico. Su responsabilidad recaería en expertos, quienes también deberían instruir a los docentes a fin de no dejar hiatos sin cubrir.

\section{Cierre y conclusiones}

Se estima oportuno efectuar aquí un cierre que habilite a quienes los desconocen o incurren en algunos de ellos a iniciar el paulatino esfuerzo que demanda enmendarlos hasta su eventual sistematización institucional.

De allí que no se abarque aquí, según se anticipara, la totalidad de "desaseos de la lengua" ni se incursione en aquellas figuras retóricas (metonimias, sinécdoques, calambur, anáfora, circunloquio, prosopopeya, comparación, metáfora y varias más) que integran un conjunto singular de recursos literarios ignorados pese a su frecuente empleo durante el aprendizaje y el ejercicio médicos.

Concluyendo, se hacen votos para la más pronta puesta en marcha de instancias compensadoras de habilidad prioritaria, a menudo olvidadas entre los muchos componentes de las denominadas competencias médicas. 


\section{Referencias bibliográficas}

- Gil Extremera, B. (2017). El correcto empleo del español. Educación Médica, 18(3) ,151-153.

- Real Academia de la Lengua Española (2019). Nueva gramática de la lengua española. Espasa Libros.

- Serra Valdés, M.A. (2016). Los epónimos médicos y la reumatología. Revista Cubana de Reumatología, 18(1), 80-86.

- Silva, R.C. (2019). El buen uso del idioma español en la literatura médica. Revista médica de Chile, 147 (5), 643-649. 